\title{
Operative Experience of U.S. General Surgery Residents with Diseases of the Adrenal Glands, Endocrine Pancreas, and Other Less Common Endocrine Organs
}

\author{
Jay K. Harness, M.D., ${ }^{1}$ Claude H. Organ, Jr., M.D., ${ }^{1}$ Norman W. Thompson, M.D. ${ }^{2}$ \\ ${ }^{1}$ Department of Surgery, University of California, Davis-East Bay, 1411 E. 31st Street, Oakland, California 94602, U.S.A. \\ ${ }^{2}$ Division of Endocrine Surgery, Department of Surgery, University of Michigan Medical Center, Ann Arbor, Michigan 48109, U.S.A.
}

\begin{abstract}
The aim of this study was to determine if the experience of general surgery residents is adequate and effective. The Resident Statistic Summaries (Report C) of the Residence Review Committee (Surgery) for eight academic years from 1986 to 1994 were analyzed. The main outcome measurements were total number of residents and programs, average number of operations performed, maximum number of operations performed, standard deviation, and the most common number of operations performed. For adrenalectomy, the average per resident was 0.98 . The maximum range was from 7 to 15 . The standard deviations ranged from 1.12 to 2.00. For pancreatic endocrine operations the average per resident was 0.15 with maximums of 3 to 10 . For other endocrine procedures (nonthyroid and nonparathyroid) the average per resident was 0.14 , with the maximums ranging from 7 to 19 . The most common number of any of these procedures performed by U.S. graduates was 0 . The number of adrenal, endocrine pancreas, and other less common endocrine procedures available for graduates of U.S. residency training programs is limited. As a consequence, most U.S. resident graduates have little or no experience with any of these procedures. Our findings suggest a strong need for fellowship training for any surgeon hoping to develop expertise in the management of these unusual and infrequent endocrine surgical diseases.
\end{abstract}

Over the past 75 years the field of endocrine surgery has evolved from its roots in operable thyroid disease to include surgical diseases of parathyroid, adrenal, pancreatic endocrine, and other organs less commonly involved with endocrine tumors. The diagnosis and treatment of operable diseases of endocrine glands require high levels of knowledge and skill. General surgery residency training programs are supposed to prepare their graduates in the primary components of the specialty, including endocrine surgery.

Recently we reported our analysis of the operative experience of U.S. general surgery residents in thyroid and parathyroid disease [1]. U.S. graduates were found to have highly variable experience in thyroid and parathyroid surgery. Most residents had inadequate experience with parathyroid surgery and marginal experience with thyroid surgery. Although most U.S. general surgery residency training programs provide their resident trainees with didactic education in endocrine surgery, the operative

Correspondence to: J.K. Harness, M.D. experience in adrenal, endocrine pancreas, and other less common sites is limited. Our study represents an analysis of the operative experience in these areas to determine if the experience of U.S. residents is adequate.

\section{Materials and Methods}

The Accreditation Council for Graduate Medical Education (ACGME) is the voluntary accrediting agency for all United States residency training programs. Graduate Medical Education (GME) programs in General Surgery are accredited by the ACGME on the recommendation of the Residency Review Committee (RRC) for Surgery. A computerized national database was started by the RRC in 1986. This database, the Surgical Operative Log (SOL), collects the total operative experience of all finishing surgical residents. There are currently 268 approved general surgery residency programs in the United States. Residency program directors report their chief resident operative experiences annually to the RRC for Surgery by diskette. Several reports are produced each year, including the Resident National Data, the Program National Data, and the Resident Statistical Summary (Report C). Report C lists five types of data for each of the listed operative categories. The data displayed are AVE (average number of operations performed by residents); MAX (maximum number of operations performed by any resident); STD (standard deviation); MODE (the most common number of operations performed); and TTL (total number of operations performed by residents). Report $\mathrm{C}$ lists the resident experience as "Surgeon," including "Total—surgeon" (all years), "Surgeonchief year," and "Surgeon-junior years." "Endocrine" is one of the 16 categories listed in Report C. Under "endocrine," the following subcategories are listed: thyroidectomy, partial or total; parathyroidectomy; adrenalectomy; pancreatic endocrine procedure; other major.

The operative experiences as "Total—surgeon" (all years) in adrenalectomy, pancreatic endocrine, and other major operations were reviewed. The data were summarized in the statistical categories listed in Report C for the academic years 1986-1987 through 1993-1994. In addition, a member of the ACGME staff 
Table 1. Resident operative experience in adrenalectomy, endocrine pancreas, and other major endocrine procedures.

\begin{tabular}{llllllllll}
\hline & \multicolumn{7}{c}{ No. operations performed, by academic years } \\
\cline { 2 - 9 } Experience & $86-87$ & $87-88$ & $88-89$ & $89-90$ & $90-91$ & $91-92$ & $92-93$ & $93-94$ \\
\hline Average & & & & & & & & \\
Adrenal & 0.8 & 0.9 & 0.9 & 1 & 0.9 & 1 & 1.2 & 1.1 \\
Pancreas & 0.1 & 0.1 & 0.1 & 0.2 & 0.1 & 0.2 & 0.2 & 0.2 \\
Other & 0.2 & 0.1 & 0.1 & 0.2 & 0.2 & 0.1 & 0.1 & 0.1 \\
Maximum & & & & & & & & \\
Adrenal & 15 & 10 & 10 & 8 & 7 & 13 & 9 & 11 \\
Pancreas & 5 & 4 & 8 & 10 & 5 & 9 & 3 & 4 \\
Other & 19 & 13 & 7 & 7 & 15 & 12 & 9 & 10 \\
STD & & & & & & & & \\
Adrenal & 1.12 & 1.24 & 1.15 & 1.19 & 1.16 & 2 & 2 & 2 \\
Pancreas & 0.45 & 0.43 & 0.53 & 0.61 & 0.46 & 1 & 1 & 1 \\
Other & 0.91 & 0.6 & 0.53 & 0.53 & 0.7 & 1 & 1 & 1 \\
MODE & & & & & & & & \\
Adrenal & 0 & 0 & 0 & 0 & 0 & 0 & 0 & 0 \\
Pancreas & 0 & 0 & 0 & 0 & 0 & 0 & 0 & 0 \\
Other & 0 & 0 & 0 & 0 & 0 & 0 & 0 & 0 \\
\hline
\end{tabular}

Adrenal: adrenalectomy; Pancreas: pancreatic endocrine; Other: other major.

analyzed the adrenalectomy, pancreatic endocrine, and other major data for 1993-1994 in terms of resident and program frequency of the numbers of operations performed. Frequency distributions were done by listing the number of procedures done, the frequency and its percent, and the cumulative frequency and percent.

\section{Results}

Table 1 summarizes the statistical data from Report $\mathrm{C}$ for the academic years 1986-1987 through 1993-1994. For adrenalectomy, the average number of operations performed as surgeon by all residents was 0.98 and ranged from a low of 0.8 to a high of 1.2. The maximum number of adrenalectomies performed by any resident during the 7 year period varied from a low of 7 to a high of 15. Standard deviations for adrenalectomy fluctuated between 1.12 and 2.00. The MODE was 0 during the academic year studies.

For pancreatic endocrine, the average number of operations was 0.15 and ranged from 0.1 to 0.2 . The maximum number of pancreatic endocrine varied from a low of 3 to a high of 10 . The standard deviations fluctuated between 0.43 to 1.00 . The MODE was 0 for all eight academic years.

For other major endocrine procedures, the average number of operations was 0.14 and ranged from 0.1 to 0.2 . The maximum number of other major endocrine procedures ranged from 7 to 19 ; the standard deviations ranged from 0.53 to 1.00; and the MODEs were consistently 0 .

The total number of chief residents and the total number of U.S. general surgery training programs from 1986 through 1994 are shown in Table 2. The highest number of finishing chief residents was 1015 (1990-1991), and the lowest was 980 (19861990). There has been a drop in the number of residency programs from a high of $289(1986-1987)$ to a low of 268 (1993-1994).

The frequency distributions of adrenalectomies, pancreatic endocrine, and other major endocrine procedures performed by
Table 2. Summary of total number of chief residents and general surgery programs.

\begin{tabular}{clllllllll}
\hline & \multicolumn{7}{l}{ No., by academic years } \\
\cline { 2 - 9 } Parameter & $86-87$ & $87-88$ & $88-89$ & $89-90$ & $90-91$ & $91-92$ & $92-93$ & $93-94$ \\
\hline $\begin{array}{c}\text { Total chief } \\
\text { residents }\end{array}$ & 995 & 991 & 1009 & 980 & 1015 & 1010 & 996 & 999 \\
$\begin{array}{c}\text { Total } \\
\text { programs }\end{array}$ & 289 & 286 & 286 & 279 & 278 & 272 & 269 & 268 \\
\hline
\end{tabular}

the 1000 finishing chief residents in 1993-1994 is shown in Table 3. A total of 375 residents had zero experience with adrenalectomy, whereas one resident did a maximum of 11 . Only one-third $(32.8 \%)$ of the finishing U.S. residents performed a minimum of one adrenalectomy. Nearly $96 \%$ of graduating U.S. residents had a low of zero adrenalectomies to a high of three.

The frequency distributions of pancreatic endocrine procedures demonstrates that nearly $85 \%$ of the graduating U.S. residents had zero experience with this procedure. Of the remaining $15 \%$, only 122 residents $(12.2 \%)$ performed at least one pancreatic endocrine operation. Thirty-two (3.2\%) of the finishing 1000 residents in 1993-1994 performed from two to a maximum of four pancreatic endocrine operations.

For the category of other major endocrine procedures, $92 \%$ of the 1000 finishing U.S. chief surgical residents had zero experience in this category. Seventy-six residents $(7.6 \%)$ did a minimum of one other major endocrine procedure to a maximum of $10 \mathrm{such}$ procedures. Reviewing the frequency distributions, the most common number of operations performed (the MODE) in all three categories was zero.

The frequency distribution of adrenalectomies, pancreatic endocrine, and other major endocrine procedures for the 268 general surgery training programs in 1993-1994 is shown in Table 4. The "number done" in the table is the average number of each procedure per finishing resident. Most of the U.S. training programs $(52.2 \%)$ averaged at least one adrenalectomy per graduating resident. Fifty-seven programs $(21.3 \%)$ had an average of zero adrenalectomies for its finishing residents. On the other hand, two programs $(0.7 \%)$ averaged four to six adrenalectomies per finishing resident.

Two hundred and nineteen $(81.7 \%)$ of U.S. training programs had zero experience in pancreatic endocrine surgery. Forty-seven $(17.5 \%)$ U.S. training programs averaged at least one pancreatic endocrine procedure per graduating resident. Two programs $(0.7 \%)$ actually averaged two pancreatic endocrine procedures per finishing resident.

The distribution for other major endocrine procedures shows that 249 programs $(92.9 \%)$ had residents graduating who averaged zero in this category. A total of 19 programs (7.0\%) had residents finishing their general surgery training averaging between one to three other major endocrine procedures.

Table 5 compares the total number of adrenal, endocrine pancreas, and other major endocrine procedures performed by residents throughout eight academic years. The table also lists the total number of all endocrine procedures (thyroidectomy, parathyroidectomy, adrenalectomy, pancreatic endocrine, and other major) done by residents for each academic year from 1986-1987 through 1993-1994. Beginning with the 1989-1990 academic year, 
Table 3. Frequency and percent of procedures performed by residents (1993-1994).

\begin{tabular}{lrrr}
\hline & & & \multicolumn{2}{l}{$\begin{array}{l}\text { Cumulative } \\
\text { No. done }\end{array}$} & Frequency & $\%$ & \multicolumn{1}{c}{$\%$} \\
\hline Adrenalectomy & & & \\
0 & 375 & 37.5 & 37.5 \\
1 & 328 & 32.8 & 70.3 \\
2 & 180 & 18.0 & 88.3 \\
3 & 74 & 7.4 & 95.7 \\
4 & 22 & 2.2 & 97.9 \\
5 & 13 & 1.3 & 99.2 \\
6 & 2 & 0.2 & 99.4 \\
7 & 5 & 0.5 & 99.9 \\
11 & 1 & 0.1 & 100.0 \\
Pancreatic endocrine & & & \\
0 & 846 & 84.6 & 84.6 \\
1 & 122 & 12.2 & 96.8 \\
2 & 24 & 2.4 & 99.2 \\
3 & 6 & 0.6 & 99.8 \\
4 & 2 & 0.2 & 100.0 \\
Other major endocrine procedures & & & \\
0 & 924 & 92.4 & 92.4 \\
1 & 59 & 5.9 & 98.3 \\
2 & 11 & 1.1 & 99.4 \\
3 & 3 & 0.3 & 99.7 \\
5 & 1 & 0.1 & 99.8 \\
6 & 1 & 0.1 & 99.9 \\
10 & 1 & 0.1 & 100.0 \\
\hline
\end{tabular}

Report $\mathrm{C}$ also lists the total number of operations performed by finishing residents in all categories.

The total number of endocrine procedures range from 15,990 to 19,042. Adrenal, pancreatic endocrine, and other major endocrine procedures constituted an average of 7\% (7.02-7.94\%) of residents' total endocrine operative experience. The total number of operations performed by residents varied from a low of 856,039 to a high of 923,010. Adrenal, endocrine pancreas, and other major endocrine procedures constituted $0.15 \%(0.14-0.16 \%)$ of the total operative experience of U.S. residents.

\section{Discussion}

The performance of effective, safe endocrine surgical procedures requires high levels of knowledge and skill. Suitable surgical skills require appropriate training. Our analysis shows inadequate experience by graduates of U.S. general surgery residency programs in adrenal, pancreatic endocrine, and other less common major endocrine surgical procedures. It appears that the primary factors contributing to their inadequate operative experience are the limited number of available cases and the limited number of medical centers that attract these unique patients. In addition, it is possible that managed care in the United States may now be diverting referrals from centers of excellence to local surgeons who may be inadequately trained to perform complex, unusual endocrine surgical procedures.

The RRC for Surgery states that "the goal of a surgical residency program is to prepare the resident to function as a qualified practitioner of surgery at the high level of performance expected of a board certified specialist." The Special Requirements for Residency Education in General Surgery further state, "The program must provide experience in preoperative, opera-
Table 4. Program frequencies (1993-1994).

\begin{tabular}{lrrr}
\hline & & & \multicolumn{2}{l}{$\begin{array}{l}\text { Cumulative } \\
\text { No. done }\end{array}$} & Frequency & $\%$ & \multicolumn{1}{c}{$\%$} \\
\hline Adrenalectomy & & & \\
0 & 57 & 21.3 & 21.3 \\
1 & 140 & 52.2 & 73.5 \\
2 & 51 & 19.0 & 92.5 \\
3 & 18 & 6.7 & 99.3 \\
4 & 1 & 0.4 & 99.6 \\
6 & 1 & 0.4 & 100.0 \\
Pancreatic endocrine & & & \\
0 & 219 & 81.7 & 81.7 \\
1 & 47 & 17.5 & 99.3 \\
2 & 2 & 0.7 & 100.0 \\
Other major endocrine procedures & & & \\
0 & 249 & 92.9 & 92.9 \\
1 & 15 & 5.6 & 98.5 \\
2 & 2 & 0.7 & 99.3 \\
3 & 2 & 0.7 & 100.0 \\
\hline
\end{tabular}

tive, and postoperative care for patients in all areas that constitute the principal components of general surgery: specifically, diseases of the head and neck; breasts; skin and soft tissue; alimentary tract; abdomen; vascular system; endocrine system; the comprehensive management of trauma, and emergency operations; and surgical critical care" [2].

To claim an operation "as surgeon," the resident must "document a significant role in the following aspects of management: determination or confirmation of the diagnosis, provision of preoperative care, selection and accomplishment of appropriate operative procedure, direction of postoperative care, and accomplishment of sufficient follow-up to be acquainted with both the course of the disease and the outcome of its treatment. Participation in the operation only, without pre- and postoperative care, is inadequate" [2].

At the conclusion of their training, chief residents are required to submit their operative experience to the RRC and the American Board of Surgery (ABS) in the form of a Surgical Operative Log (SOL). The SOLs are collected by the RRC and the data used to create annual reports. Apparently only one paper in the literature has attempted to evaluate the accuracy of residents' SOLs. Coe and colleagues found that the overall reporting accuracy of their institutional SOLs was excellent [3].

During the eight academic years studied, adrenalectomy was the most common procedure performed of the three categories under review. The average per resident for the 8 years was barely one per resident (0.98). During 1993-1994, more than one-third $(37.5 \%)$ of residents did zero adrenalectomies, and another one-third $(32.8 \%)$ performed only one. The remaining residents performed an average of two to a maximum average of 11 adrenalectomies.

The limited number of adrenalectomies available for training residents in the U.S. means that these procedures are probably not well distributed among the 268 training programs. Such is the case. One-fifth $(21.3 \%)$ of the programs averaged zero experience in adrenalectomy for their graduating residents. One-half $(52.2 \%)$ of the programs averaged only one adrenalectomy per resident, and the remaining one-fourth $(26.5 \%)$ had residents who averaged two to six adrenalectomies.

Adrenalectomy is more than a technical exercise in surgical 
Table 5. Comparison of adrenalectomy, endocrine pancreas, and other major endocrine operations performed with total endocrine and total all other operations.

\begin{tabular}{|c|c|c|c|c|c|c|c|c|}
\hline \multirow[b]{2}{*}{ Operation } & \multicolumn{8}{|c|}{ Results by academic years } \\
\hline & $86-87$ & $87-88$ & $88-89$ & $89-90$ & $90-91$ & $91-92$ & $92-93$ & $93-94$ \\
\hline \multicolumn{9}{|l|}{ All operations } \\
\hline Other & 173 & 138 & 135 & 156 & 173 & 148 & 112 & 111 \\
\hline Total & 1,133 & 1,203 & 1,181 & 1,322 & 1,269 & 1,384 & 1,472 & 1,426 \\
\hline Total endocrine operations & 16,144 & 15,990 & 16,573 & 16,643 & 17,546 & 18,099 & 18,939 & 19,042 \\
\hline Total operations & NG & NG & NG & 856,039 & 908,762 & 914,812 & 918,208 & 923,010 \\
\hline$\%$ Adrenal, pancreas, other & - & - & - & 0.15 & 0.14 & 0.15 & 0.16 & 0.15 \\
\hline
\end{tabular}

Adrenal: adrenalectomy; Pancreas: pancreatic endocrine; Other: other major operations; NG: not given.

resection. The operating surgeon must be knowledgeable in the diagnostic techniques used to determine the correct preoperative diagnosis and the medical management of the underlying pathologic condition. Intraoperative and postoperative management must also be critical components of the surgeon's knowledge base and expertise. These statements are equally important for pancreatic endocrine and other less common operable endocrine conditions.

What about the faculty who are teaching the residents? What is their level of experience and expertise? These questions are difficult to answer, as there are no reports that quantify faculty operative experience.

The International Association of Endocrine Surgeons (IAES) and the American Association of Endocrine Surgeons (AAES) surveyed its members in 1993 and again in 1995. The questionnaire that was circulated asked each program to quantify the number of endocrine surgeons at their institution, as well as the number of endocrine procedures performed. Only 117 institutions responded worldwide. An average of 11 (10.769) adrenalectomies were performed per year at these institutions by 265 "endocrine surgeons" (an average of 4.76 per endocrine surgeon) [4]. All of the reporting institutions are teaching hospitals. Although the survey was not an in-depth scientific study, it does appear to provide general information about the experience of endocrine surgeons around the world. It also implies that the "teachers" of endocrine surgery have limited experience in adrenalectomy. As will be seen, the same is true for pancreatic endocrine and other less common major endocrine procedures.

Our analysis shows limited experience in both pancreatic endocrine and other less common endocrine procedures. For pancreatic endocrine operations, the average is 0.15 per resident and for other less common major procedures the average is 0.14 . The number of these procedures available for residency training in the U.S. is limited. For the eight academic years studied, the maximum number of pancreatic endocrine procedures performed by U.S. residents during 1993-1994 was 195. For less common major endocrine procedures, the maximum number during 1990-1991 was 173 (Table 5).

The IAES/AAES survey found that the average endocrine surgeon did two endocrine pancreas, two gastrointestinal endocrine, and one other less common major endocrine surgical procedures per year. The survey indicates that the endocrine surgical faculty also have limited experience in these unusual procedures.

Table 4 shows the program frequencies of the procedures under study. About $82 \%$ of U.S. residency programs have no operative experience in pancreatic endocrine. Similarly, more than $90 \%$ have no experience in other less common endocrine procedures. Forty-nine U.S. programs (18.2\%) report any experience with endocrine pancreas procedures, and only 19 programs (7.0\%) report any experience with the less common procedures. No detail has been provided by ACGME staff as to where these 49 and 19 programs are located. We assume that most of these programs are in major university teaching centers.

Table 5 puts our analysis in perspective when reviewing the adrenal, pancreatic, and less common procedures against U.S. residents' overall endocrine surgical experience and their total operative experience. The procedures under study in our review average only $0.15 \%$ of the total operative experience of graduating U.S. general surgery residents. These procedures also only constitute $7.8 \%$ of residents' entire endocrine surgical experience. Thyroidectomy is far and away the most common endocrine operative procedure done, followed by parathyroidectomy. Thyroidectomy accounts for two-thirds of U.S. residents' overall endocrine surgical experience, and parathyroidectomy accounts for only one-fourth of their endocrine surgical experience [1].

What is the minimum operative experience to be considered a safe surgeon? The RRC for Surgery has addressed that issue by defining minimum numbers of operations in its primary components of general surgery (Table 6) [5]. The minimum number for head and neck is 24 and for endocrine is 8 . Thyroid and parathyroid operations can be counted in both head and neck and endocrine categories. Adrenal, pancreatic endocrine, and other less common endocrine procedures are usually counted in the endocrine category.

Managed care is a phenomenon that is sweeping the United States. It will eventually push general surgeons to perform endocrine surgical procedures that allegedly fall within their expertise as a result of their training and board certification, even though they may have had little, if any, experience. Whether the surgeon does the procedure is up to the conscience of the individual, which today may be influenced by managed care pressures. Board certification and credentialing do not guarantee the public real expertise and proficiency. We believe that our study demonstrates 
Table 6. RRC guidelines for minimum operative procedures.

\begin{tabular}{lr}
\hline Components & No. \\
\hline Primary & \\
Skin, soft tissues, breast & 25 \\
Head and neck & 24 \\
Alimentary tract & 72 \\
Abdomen & 65 \\
Liver & 4 \\
Pancreas & 3 \\
Vascular system & 44 \\
Endocrine & 8 \\
Trauma & 16 \\
Secondary & \\
Thoracic & 15 \\
Pediatric & 20 \\
Plastic & 5 \\
Endoscopy & 29 \\
\hline
\end{tabular}

an inadequate experience by U.S. graduates in adrenal, pancreatic endocrine, and less common endocrine surgical procedures.

Our findings suggest a strong need for fellowship training for any surgeon hoping to develop expertise in the management of these unusual and infrequent endocrine surgical diseases. The few cases that are available in the United States for resident training appear to be limited to major academic medical centers. These centers would be logical locations for endocrine surgical fellowship training. The International Association of Endocrine Surgeons has recently released its directory on endocrine surgery programs and available fellowships [4]. The fellowships that are currently available are located at centers that have extensive experience in most all aspects of endocrine surgery. No formalized structure has been proposed for these fellowships. In the United States the American Association of Endocrine Surgeons (AAES) is the logical organization to propose guidelines and structure for endocrine surgical fellowships. Their deliberations on this subject should be done in concert with the American Board of Surgery and the RRC for Surgery. Internationally, the IAES seems to be an appropriate organization to provide leadership in the arena of endocrine surgical fellowships. Undoubtedly, the IAES will work in concert with various regional and national endocrine surgical associations located in Europe and Asia.

In an era when governments, managed health care organizations, and others are telling physicians and surgeons what to do, the time has come for physicians to reassert their leadership. The development of endocrine surgical fellowships is one example of that process. Patients with endocrine surgical diseases, especially those that are complex and uncommon, should be referred to appropriately trained and experienced endocrine surgeons. To do otherwise will increase the number of poor outcomes and complications experienced by patients with surgical diseases of endocrine glands.

\section{Résumé}

Objectives: Déterminer si l'expérience des résidents (internes) en chirurgie générale est suffisante et efficace. Méthodes: Les résumés du rapport «Resident Statistic Summaries» (Report C) provenant du Comité «Residence Review Committee» pendant les huit années académiques 1986-1994 ont été analysés. Les critères de jugement principaux étaient le nombre total de résidents et leurs programmes, le nombre moyen d'interventions réalisées, le nombre maximum d'interventions réalisées y compris les variations et le mode statistique. Résultats: Pour la surrénalectomie, le nombre moyen d'interventions a été de 0.98. Le maximum d'interventions réalisés allait de 7 à 15 . Les écart-type allaient de 1.12 à 2. Pour le pancréas endocrine, la moyenne par résident a été de 0.15 avec un maximum de 3 à 10 . Pour les autres procédés de chirurgie endocrine (nonthyroïdiens, nonparathyroïdiens), la moyenne par résident a été de 0.14 avec des maximums allant de 7 à 19 . Le mode pour ces procédés a été de 0 pour les diplômés provenant des Etats-Unis. Conclusions: Le nombre de surrénalectomies, des interventions sur le pancréas endocrine et des autres procédés existants reste limité pour les résidents aux Etats Unis est limité. Par conséquence, la majorité des résidents a peu sinon pas d'expérience de ces procédés. Nos données suggèrent le besoin manifeste de développer des programmes d'enseignement pratique pour permettre aux résidents de développer les gestes pratiques nécessaires à ces interventions endocriniennes peu fréquentes.

\section{Resumen}

Objetivo: determinar si la experiencia de los residentes de cirugía general es adecuada y efectiva. Métodos: Se analizaron los Residents Statistics Summaries (Report C) del Residence Review Committee (Cirugía) correspondientes a ocho años académicos en el período 1986-1994. Las principales mediciones de resultados fueron: número total de residentes y programas; promedio de operaciones realizadas; número máximo de operaciones realizadas; desviación estándar; y el número más común de operaciones realizadas. Resultados: En cuanto a adrenalectomía, el promedio por residente fue 0.98; el rango máximo de 7 a 15 . La desviación estándar tuvo un rango de 1.2 a 2 . En cuanto a cirugía pancreática endocrina, el promedio por residente fue 0.15 con máximos de 3 a 10. Otros procedimientos endocrinos (no tiroideos \& no paratiroideos) mostraron un promedio por residente de 0.14 y máximo tuvo un rango de 7 a 19. El número más común de estos procedimientos realizados por los graduados de EUA fue 0 . Conclusiones: el número de procedimientos adrenales, pancreáticos endocrinos y otros procedimientos endocrinos menos comunes, disponibles para graduados de programas de adiestramiento en residencia en EUA es extremadamente limitado. Como consecuencia, la mayoría de los graduados de residencias en EUA tienen poca o ninguna experiencia en cualquiera de estos procedimientos. Nuestros hallazgos sugieren una fuerte necesidad de adiestramiento en fellowship para un cirujano que pretenda adquirir idoneidad en el manejo de estas inusuales e infrecuentes enfermedades endocrinas quirúrgicas.

\section{Acknowledgments}

The authors thank Dr. Jack Boberg, Mr. Jerry Vasilias, and the staff of the Residency Review Committee for Surgery for their invaluable assistance in providing the data and analyses used in the preparation of this article. 


\section{References}

1. Harness, J.K., Organ, C.H., Jr., Thompson, N.W.: Operative experience of U.S. general surgery residents in thyroid and parathyroid disease. Surgery 118:1063-70, 1995

2. Graduate Medical Education Directory 1994-1995. Chicago, American Medical Association, 1994

3. Coe, N.P.W., Garb, J.L., Lincoln, K.J., Friedmann, P.: Evaluation of accuracy of reporting residents' operative experience. Am. J. Surg. 159:615, 1990

4. Harness, J.K., editor: World Directory of Endocrine Surgery Programs and Fellowship Opportunities, 1st edition, Oakland, International Association of Endocrine Surgeons, 1995

5. New operative guidelines. In: RRC for Surgery Newsletter. Chicago, Accreditation Council for Graduate Medical Education August 1991, pp. 1-2

\title{
Invited Commentary
}

\author{
Richard A. Prinz, M.D.
}

Department of General Surgery, Rush-Presbyterian-St. Luke's Medical Center, Rush University, Chicago, Illinois, U.S.A.

Harness and coworkers have used the computerized database of the Residency Review Committee (RRC) for Surgery to evaluate the experience of chief residents graduating from approved U.S. training programs in adrenal, pancreatic, and other nonthyroid or nonparathyroid endocrine surgery. This database is called the Surgical Operative Log (SOL) and collects the operative experience submitted by all surgical residents at the completion of their training. In a previous study, the authors used similar methods to evaluate the number of thyroid and parathyroid operations performed by residents during their 5 years of surgical training [1]. Not surprisingly, both studies document that surgeons currently have a limited exposure to endocrine surgery during residency training. The present study shows that the average chief resident barely performs one adrenalectomy and rarely if ever performs a pancreatic endocrine procedure ( 0.15 cases/resident $)$ or a major nonthyroid, nonparathyroid endocrine procedure ( 0.14 cases/ resident). More than one-third of graduating chief residents have not performed an adrenalectomy and another third have performed only one. No operative experience with the endocrine pancreas and with major nonthyroid, nonparathyroid endocrine procedures was found in $82 \%$ and $93 \%$, respectively, of U.S. surgical training programs. The prior study found that the average number of thyroidectomies performed during residency by chief residents who finished their training between 1987 and 1994 ranged from 10.8 to 12.7 [1]. The average number of parathyroidectomies done by these same residents ranged from 4.1 to 5.1. Twenty-six percent of residents completing residency in 1994 performed two or fewer parathyroidectomies. There is little reason to question the SOL data, which form the basis of these findings. The only study that has evaluated its veracity was done by Coe and coworkers, who corroborated its accuracy [2].

The authors suggest two reasons for these results: limited numbers of patients needing these endocrine operations and changes in referral patterns mediated by managed care. Limited case availability is a global issue in surgical education. General surgery is a broad discipline composed of nine primary components, each of which covers many common and uncommon problems. A number of procedures in most of the primary components are infrequently if ever performed by many residents and practicing surgeons. Obvious examples are liver resection, pancreaticoduodenectomy, and portocaval shunts. Clearly from

the findings in these studies, certain endocrine procedures fall into this same category. Surgical educators have grappled with the problems posed by limited case availability for some time. One suggestion for dealing with the issue is to change the structure of residency training so general surgical cases that are scarce are not wasted on surgeons going into other disciplines, such as plastic or cardiac surgery. Issues of continuity of care and of comparability of training are posed by this approach. Another proposal is to create fellowships as a means to provide in-depth training in areas not well covered in many residencies. This is a two-edged sword, as it potentially dilutes the general surgical resident's exposure to these cases.

The effect of managed care on these findings is certainly open to question. The study covers eight academic years (1986-1994) and all regions of the country. Obviously, the penetrance of managed care has varied highly with time and place. Even so, it is appropriate to ask whether the economic self-interest of managed care organizations is well served by their directing patients with unusual and difficult surgical problems to inexperienced surgeons. The complexities of endocrine surgery and for adrenal and endocrine pancreatic problems in particular involve diagnosis, localization, preoperative preparation, choice of operative approach, special anatomic and technical procedural demands, postoperative care, and follow-up. Many resources can be squandered if the surgeon is not familiar and experienced with all of these items. Lack of training leads not only to inappropriate and inefficient use of resources but also to poor patient outcomes. The increased costs of treating patients who have had an inadequate initial operation for hyperparathyroidism have been well documented [3]. Likewise, lower costs and better outcomes have been achieved in centers specializing in nonendocrine pancreatic surgery [4]. Thus it seems from an economic viewpoint that it would be most cost-effective to have those competent in endocrine surgery treat the unusual and complex endocrine surgical diseases.

The question then becomes: How do we create competence in our surgical trainees and how do we demonstrate that competence to our patients and to managed care or other organizations that pay for their health care? Certainly, competence is not simply a matter that can be measured by counting numbers of cases performed. Those who are interested in endocrine surgical education should be exploring new teaching methods and new technologies, such as virtual reality simulations rather than setting number of case criteria for their trainees. Likewise, meaningful outcome measures are needed to judge the efficacy of training programs and methods and of clinical approaches and interventions.

The tension between fragmentation and specialization is percolating in endocrine surgery. Surgeons and educators, especially 
those with an interest in endocrine surgery, must come to grips with the stresses and strains that have developed. Innovative and creative solutions are needed to ensure that most general surgeons are competent to do common, straightforward endocrine procedures, and that some general surgeons are competent to perform unusual and complex procedures. As general surgery continues to evolve, the interests and clinical activities of many practicing general surgeons often seem to gravitate to particular areas in the discipline. This specialization can upgrade the training of all surgical residents and focus the education of a few on the excellence needed for unusual patient problems and the broad demands of teaching. Personal economic and competitive issues must be put aside to resolve this matter. Our trainees and our patients both expect and deserve to receive competence from their surgeons.

\section{References}

1. Harness, J.K., Organ, C.H., Jr., Thompson, N.W.: Operative experience of U.S. general surgery residents in thyroid and parathyroid disease. Surgery 118:1063, 1995

2. Coe, N.P.W., Garb, J.L., Lincoln, K.H., Friedmann, P.: Evaluation of the accuracy of reporting residents' operative experience. Am. J. Surg. 159:615, 1990

3. Doherty, G.M., Weber, B., Norton, J.A.: Cost of unsuccessful surgery for primary hyperparathyroidism. Surgery 116:954, 1994

4. Gordon, T.A., Burleyson, G.P., Tielsch, J.M., Cameron, J.L.: The effects of regionalization on cost and outcome for one general high-risk surgical procedure. Ann. Surg. 221:43, 1995 